\title{
Restrained eating and self-esteem in premenopausal and postmenopausal women
}

\author{
Suzana Drobnjak', Semra Atsiz ${ }^{1}$, Beate Ditzen ${ }^{1,3}$, Brunna Tuschen-Caffier $^{2}$ and Ulrike Ehlert ${ }^{1 *}$
}

\begin{abstract}
Background: There has been limited research about disordered eating in middle-aged women, and to date, few data exist about restrained eating behavior in postmenopausal women. Therefore, the aim of this study was to examine eating behavior with a specific focus on menopause as an associated factor in restrained eating. Beyond this, we were interested in how postmenopausal status and self-esteem would interact to determine eating patterns in women in middle age.

Methods: We conducted an online survey in women aged between 40 and 66 . Eating behavior was assessed with the Eating Disorder Examination-Questionnaire (EDE-Q) in premenopausal $(N=318)$ and postmenopausal women $(N=250)$. All participants rated their self-esteem using the Rosenberg Self-Esteem Scale (RSE) and reported their weight, height, waist circumference, and hip circumference.

Results: $15.7 \%$ of all participants showed clinically meaningful scores on restrained eating. Postmenopausal women showed significantly higher scores on the EDE-Q subscale of restrained eating as compared to premenopausal women, but when controlling for body mass index, however, this finding was no longer significant. Further exploratory analyses suggest that particularly low or high self-esteem levels are associated with restrained eating. Self-esteem might serve as a mediator between menopausal status and restrained eating, however results of these additional analyses were inconsistent.
\end{abstract}

Conclusions: Restrained eating may appear in middle-aged women. Particularly in postmenopausal women, restrained eating might be associated with lower and higher self-esteem.

Keywords: Menopause, Middle age, Restrained eating, Self-esteem, Eating behavior

\section{Background}

An increasing number of middle-aged women from highly industrialized countries are practicing disordered eating behaviors [1]. Eating disorders often show a chronic course, functional impairment, and seem to increase the risk of several health problems such as future obesity, depressive disorders, suicide attempts, anxiety disorders, and substance abuse [2]. Besides clinically diagnosed eating disorders such as anorexia nervosa and bulimia nervosa [3], disordered eating includes a wide range of eating-related problems [4]. Such behavior occurs relatively frequently but does not meet full criteria for the diagnosis of an eating disorder [4,5]. In general, disordered eating is a well-researched phenomenon,

\footnotetext{
* Correspondence: u.ehlert@psychologie.uzh.ch

'Department of Psychology, Division of Clinical Psychology \& Psychotherapy, University of Zurich, Binzmuehlestrasse 14/26, Zurich 8050, Switzerland

Full list of author information is available at the end of the article
}

which is mainly assessed in adolescent and young adult women [3]. So far, few studies have investigated disordered eating in women between the ages of 40 and around 65 years [6], although health professionals have recently begun to focus their attention on disordered eating among this age group [7]. Admissions of middleaged women to eating disorder inpatient treatment has increased over the last ten years $[8,9]$.

Although in several studies, restrained eating has been identified as a main risk factor for young women to develop an eating disorder [10], as yet, specific trajectories of eating disorders in middle-aged women remain unknown. In general, restrained eating is defined as an intentional restriction of energy intake with the aim of losing or controlling weight [11]. Despite this definition, several studies indicate that restrained eating predicts

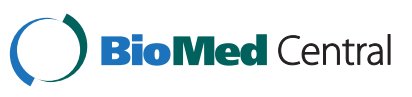


weight gain and might be a risk factor for future onset of obesity [12,13].

Several studies found biological (e.g. body mass index), psychological (e.g. self-esteem), and sociocultural influences (e.g. weight-related teasing) [1] to predict disordered eating patterns - and these seem to be independent of age. However, a specific factor associated with eating behavior in middle-aged women might be menopause status. Menopause is defined as the permanent cessation of the primary functions of the human ovaries [14]. Menopause can be determined retrospectively, once 12 months have elapsed with no menstrual cycle, and this time frame distinguishes menopause from other related terms such as premenopause, perimenopause and postmenopause [14]. Premenopause describes a period of time with regular menstrual cycles. Perimenopause is a period of time when menstrual cycles begin to become irregular. Finally, postmenopause starts after the final menstrual period. After 12 months of amenorrhea, it can be determined that a woman has entered postmenopause [14].

Menopausal transition is a complex psychophysiological process [14]. During the menopausal transition, women could gain an average of 2 to $2.5 \mathrm{~kg}$ in weight over 3 years, which is often regarded as the major contributing factor to midlife body weight gain in women [15]. Besides this, it has been shown that a shift to an abdominal fat redistribution occurs [16]. Since slimness is an important criterion of female attractiveness in many societies $[17,18]$, it can be assumed that middleaged women may experience a loss of attractiveness due to the age-related naturally occurring weight gain [19]. However, the data regarding body image in this age group are contradictory. Although researchers found that the perception of attractiveness is not influenced by age or menopausal status [19], postmenopausal women reported less positive attitudes about their appearance than premenopausal women [20].

Overall, body weight and female self-experienced attractiveness are closely connected, as are self-rated attractiveness and self-esteem [21]. Additionally, as supported by meta-analyses, self-esteem seems to be associated with disordered eating [22]. Lower self-esteem, which means a reduced sense of contentment, self-acceptance, and a reduced appraisal of one's own worth, predicts higher rates of eating disorders in young women [22-25] and body dissatisfaction or symptoms of bulimia nervosa in middleaged women $[7,26,27]$.

Our study was designed with two aims: first, to examine the association between menopausal status and disordered eating, with a particular focus on restrained eating in middle-aged women. Our hypothesis was that postmenopausal women will show increased scores in disordered eating than premenopausal women. Our second aim was to examine the role of self-esteem in disordered eating in this age group. We hypothesized that low self-esteem will be positively associated with disordered eating in postmenopausal women.

\section{Methods}

\section{Data collection and participants}

Potential participants were contacted by email using mailing lists and websites from women's organizations (e.g. www.frauenlandsgemeinde.ch) in Switzerland. The information of the advertisement in the internet in order to inform and recruit the women contained a brief explanation about the study: We introduced the background of the study with the fact that little has been known about eating behavior and related factors in middle-aged women. After this short introduction we informed potential study participants that the online questionnaire would contain questions about demographics, their eating behavior, psychological variables, and menstrual cycle status. Email recipients were also informed that the online survey would take about 15 minutes. The inclusion criteria was age over 40 and female gender. At the end of our information letter, we referred to the link, which had to be opened in order to get to the questionnaire. The survey was programmed using the software Unipark (http://www.unipark.info/1-0online-befragungssoftware-fuer-studenten-und-universitaeten-unipark-home.htm). Overall, we sent about 5'000 Email invitations and 1101 potential participants started to fill out our questionnaire. The drop-out rate (participants who did not fill out the questionnaire completely) in our study was $40.2 \%$.

Participation in the study was voluntary and all women gave their informed consent. Only participants who agreed with the informed consent were able to fill out the questionnaire. Upon completion of the questionnaire, the participants were thanked for their filling in the questionnaire and informed that their anonymity would be guaranteed. Participants who were interested in a follow-up study or who wished to receive further information on the study results could leave their e-mail addresses. Additionally, contact information was provided for the unlikely event that responding to stress or symptom-related questions caused acute psychological problems. This study was conducted in accordance with rules and regulations of the appropriate ethics committee (The Faculty of Arts and Humanities of the University of Zurich, Switzerland).

We excluded participants with the following criteria: age under 40 or over 66, pregnancy, self-reported Affective Disorder, Eating Disorder or Anxiety Disorder, last menstruation more than 15 years ago and participants who did not complete all questions. After the completion of the study, menopausal status was defined as follows: premenopausal women $(\mathrm{N}=318)$ reported 
to have a regular or irregular menstrual cycle in the past 12 months, which means that participants with a possible perimenopausal status were in the group premenopausal women included, too. Postmenopausal women $(\mathrm{N}=250)$ had not had a menstrual cycle during the past 12 months. The women were asked to provide the date (day, month, year) of their last menstruation. The detailed process of recruitment and the selection of the two groups from a large sample are shown in Figure 1.

\section{Assessment measures}

The online survey consisted of 58 items. The first section of questions comprised items addressing sociodemographic, general health-related, and menstrual cycle-related variables. The second section of the survey consisted of questions about eating behavior and self-esteem, presented in a randomized order.

\section{Body Mass Index and Waist-to-Hip Ratio}

Participants were asked to indicate their weight and height, and BMI was calculated as weight divided by the square of height in $\mathrm{cm}$. Besides this, participants were asked to measure their waist (at the midpoint between the lower margin of the last palpable rib and the top of the iliac crest) and hip circumference (widest portion of the buttocks) [28]. Waist-to-hip ratio (WHR) was calculated by dividing the waist by the hip circumference [28]. In addition, we illustrated the definition of the WHR measurement with a picture. WHO norms [28] define obesity for females as a WHR above 0.85 , or a BMI above 30 ). BMI and WHR were used as control variables in this study.

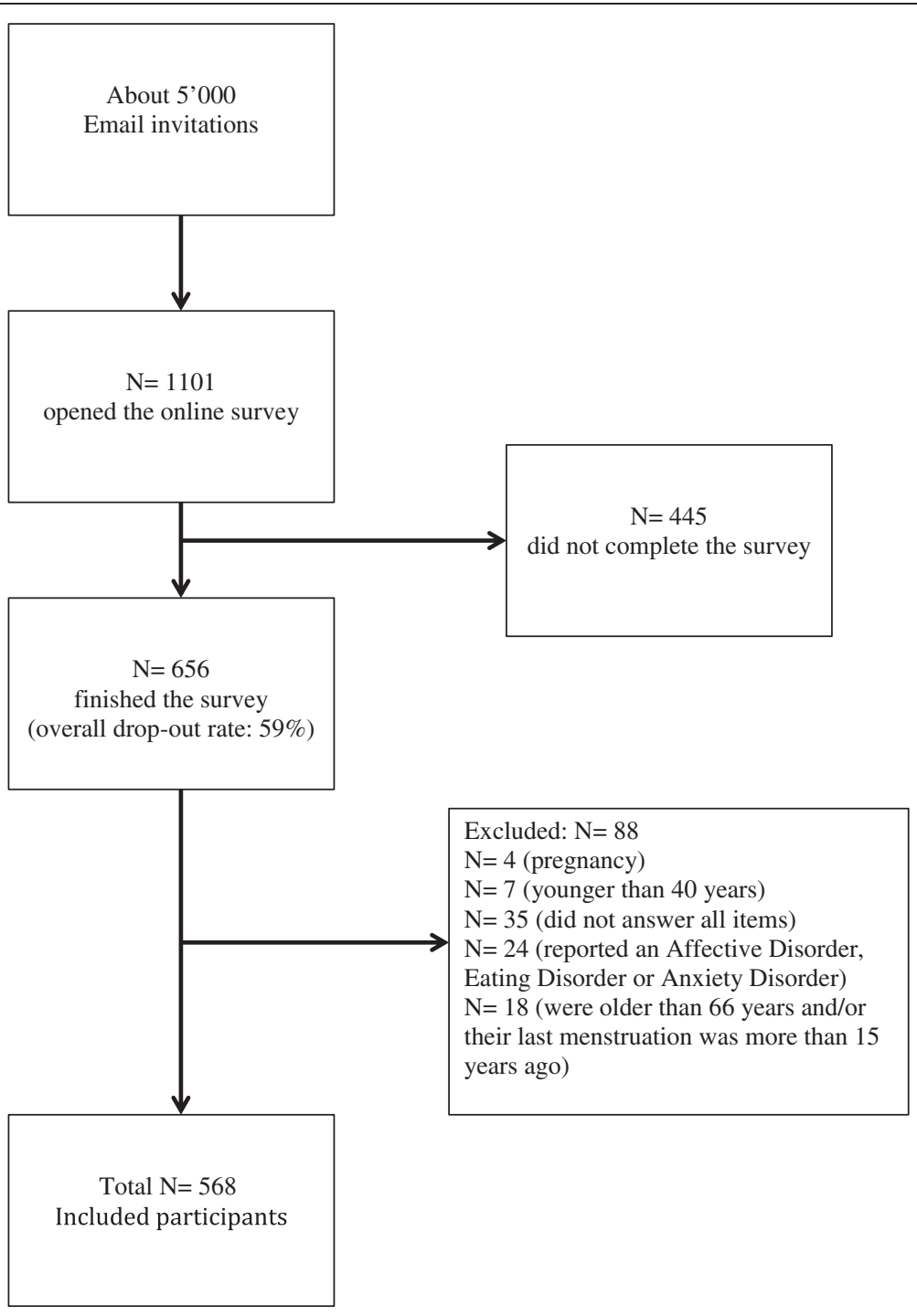

Figure 1 Process of data selection. 


\section{Eating behavior}

Eating behavior was assessed with the German version of the Eating Disorder Examination-Questionnaire (EDE-Q) $[29,30]$. The EDE-Q is a self-report instrument with 36 items covering the previous 28 days. It contains four subscales measuring restrained eating, shape concern, weight concern, and eating concern, to be summarized with a global score. The items can be answered on a 7-point scale, with higher scores reflecting greater eating-related pathology. Frequencies of disordered eating behaviors including binge eating and various compensatory behaviors are also assessed. Based on this questionnaire, "extreme dietary restraint" was defined with reference to the EDE-Q "food avoidance" item, namely "going without food for a period of eight or more waking hours on average three or more times per week in order to influence weight or shape" [31,32]. For the EDE-Q, norms for anorexia nervosa, bulimia nervosa, and eating disorders not otherwise specified are available for young women $[29,30,33]$. The scores of the subscale "restrained eating" range from 0.1 to 2.6 among women without diagnosed eating disorders, while means of restrained eating between 2.7 and 6 are found in women with eating disorders. Women with clinically meaningful scores show values ranging between 3.7 and 6.0 for "shape concern", between 3.09 and 6.0 for "weight concern", and between 1.85 and 6 for "eating concern" [30].

Additional six items measure diagnostically relevant information, e.g. symptoms of binge eating. In our study, we analyzed the item 13 "Over the past 28 days, how many times have you eaten what other people would regard as an unusually large amount of food (given the circumstances)?" and item 14 "On how many of these times did you have a sense of having lost control over your eating (at the time you were eating)?". These key behavioral items were dichotomized for any occurrence $(\geq 1$ episode versus 0 episodes over the past 28 days) and regular occurrence ( $\geq 4$ or $<4$ episodes in the last 28 days) [31].

In this study, the Cronbach's alpha for each subscale was acceptable (restrained eating $=.78$; shape concern $=.89$; weight concern $=.77$; eating concern $=.82$ ).

\section{Self-esteem}

Self-esteem was assessed with the German version [34] of the self-esteem scale (RSE) [35], which is a widely used self-esteem inventory in social science research. The scale contains 10 items to be scored from 1 = "totally disagree" to $4=$ "totally agree". Negatively coded items were recoded in order to calculate the sum score. In the present study, the Cronbach's alpha for SES was .74, which is acceptable.

\section{Data analysis}

Following overall descriptive data analysis and the analysis of frequencies and intensities of disordered eating behavior, and the key behavioral factors for binge eating, premenopausal women and postmenopausal women were compared with regard to eating behavior, such as restrained eating, shape concern, eating concern and weight concern, using multivariate ANOVAs. Furthermore, BMI, age and WHR were included as covariates, and univariate ANOVAs with menopause status as factor and restrained eating or selfesteem as dependent variables were conducted. An additional univariate ANOVA was performed with menopause status as factor and "extreme dietary restraint" as dependent variable including the control variables BMI, age and WHR.

\section{Results}

\section{Participants' characteristics}

Table 1 provides descriptive data of the total study sample ( $\mathrm{N}=568$ women, aged from 40 to 66 years).

\section{Frequencies and intensities of disordered eating behavior} $80.8 \%(\mathrm{~N}=459)$ of all participants show a score higher than 0 on restrained eating. $15.7 \%(\mathrm{~N}=116)$ of the participants show clinically relevant scores on restrained eating. 10.7\% $(\mathrm{N}=61)$ participants reported "Extreme dietary restraint", defined as going without food for a period of eight or more waking hours on average three or more times per week. Of these 61 participants, one participant reported a $\mathrm{BMI}<18.5,42$ a BMI between 18.5 and 25, and 18 women reported a BMI over 25 .

Comparable scores were found in the subscales eating concern, weight concern and shape concern, with 56.9\% to $82 \%$ of all participants reporting low to moderate manifestations of disordered eating. $6 \%$ to $12.5 \%$ reported clinically meaningful scores on these subscales. Figure 2 displays the distributions of eating patterns.

In addition, results of the key behavioral features showed the following results: $69.7 \%(\mathrm{~N}=396)$ showed no occurrence of eating large amounts of food (EDE-Q item 13), whereas $30.3 \%(\mathrm{~N}=172)$ scored higher than 1. $86.7 \%(\mathrm{~N}=493)$ reported no regular occurrence of this behavior whereas $13.3 \%(N=75)$ showed scores higher than $4.77 .5 \%(\mathrm{~N}=440)$ showed no occurrence of lost control during eating (EDE-Q item 14), whereas 22.5\% $(\mathrm{N}=128)$ scored higher than 1. 89.2\% $(\mathrm{N}=507)$ reported no regular occurrence of this behavior whereas $10.8 \%$ $(\mathrm{N}=61)$ showed a score over 4 .

\section{Correlations between eating behavior and associated variables}

Most correlations were significant at the .001 level, except for WHR and menstrual status, where the associations with the other variables were mostly insignificant (see Table 2). 
Table 1 Characteristics of study population

\begin{tabular}{|c|c|c|c|}
\hline Characteristics & Premenopausal $(\mathrm{N}=318)$ & Postmenopausal $(\mathrm{N}=250)$ & Group difference t-test/Chi-square \\
\hline$\overline{\text { Age }}$ & $M=46.40, S D=3.96$ & $M=54.98, S D=5.19$ & $\mathrm{~T}=-22.499, \mathrm{p}=.000$ \\
\hline \multicolumn{4}{|l|}{ Education } \\
\hline Any type of college and higher & $N=228(71.7 \%)$ & $N=139(49.6 \%)$ & $x^{2}=6.698, p=.153$ \\
\hline \multicolumn{4}{|l|}{ Marital status } \\
\hline Married/in a relationship & $N=200(62.9 \%)$ & $N=190(76.0 \%)$ & $x^{2}=0.536, p=.464$ \\
\hline Single/separated/divorced & $N=118(37.1 \%)$ & $N=60(24.0 \%)$ & $x^{2}=1.002, p=.317$ \\
\hline Employment & $76-100 \%$ & $N=152(47.8 \%)$ & $N=95(38.0 \%)$ \\
\hline unemployed/up to $75 \%$ & $N=166(52.2 \%)$ & $N=155(62.0 \%)$ & $x^{2}=3.003, p=.391$ \\
\hline Children & $\mathrm{M}=1.4, \mathrm{SD}=.49$ & $M=1.26, S D=.44$ & $\mathrm{~T}=-1.144, \mathrm{p}=.253$ \\
\hline Months after beginning of the last menstruation & $M=1.00, S D=1.79$ & $M=97.81, S D=68.36$ & $\mathrm{~T}=24.497, \mathrm{p}=.000$ \\
\hline BMI & $M=23.34, S D=3.86$ & $M=23.74, S D=4.53$ & $T=-1.133, p=.258$ \\
\hline WHR & $M=0.812, S D=0.07$ & $M=0.828, S D=0.09$ & $T=-1.758, p=.080$ \\
\hline EDE-Q_restrained & $M=1.23, S D=1.32$ & $M=1.45, S D=1.35$ & $\mathrm{~T}=-1.983, \mathrm{p}=.048$ \\
\hline EDE-Q_eating & $M=0.46, S D=0.87$ & $M=0.48, S D=0.82$ & $\mathrm{~T}=-0.295, \mathrm{p}=.768$ \\
\hline EDE-Q_weight & $M=1.28, S D=1.29$ & $M=1.29, S D=1.27$ & $\mathrm{~T}=-0.080, \mathrm{p}=.936$ \\
\hline EDE-Q_shape & $M=1.63, S D=1.45$ & $M=1.67, S D=1.47$ & $T=-0.305, p=.761$ \\
\hline RES & $M=39.77, S D=4.64$ & $M=38.86, S D=4.82$ & $\mathrm{~T}=2.288, \mathrm{p}=.023$ \\
\hline
\end{tabular}

Note: $\mathrm{EDE}-\mathrm{Q}_{\text {restrained }}$ subscale restrained eating of the EDE-Q; $\mathrm{EDE}-\mathrm{Q}$ eating $=$ subscale eating concern of the EDE-Q; EDE-Q weight = subscale weight concern of $\mathrm{EDE}-\mathrm{Q} ; \mathrm{EDE}-\mathrm{Q}$ shape = subscale shape concern of the EDE-Q; $\mathrm{BMI}=$ body mass index; $\mathrm{RSE}=$ Rosenberg Self-Esteem Scale.

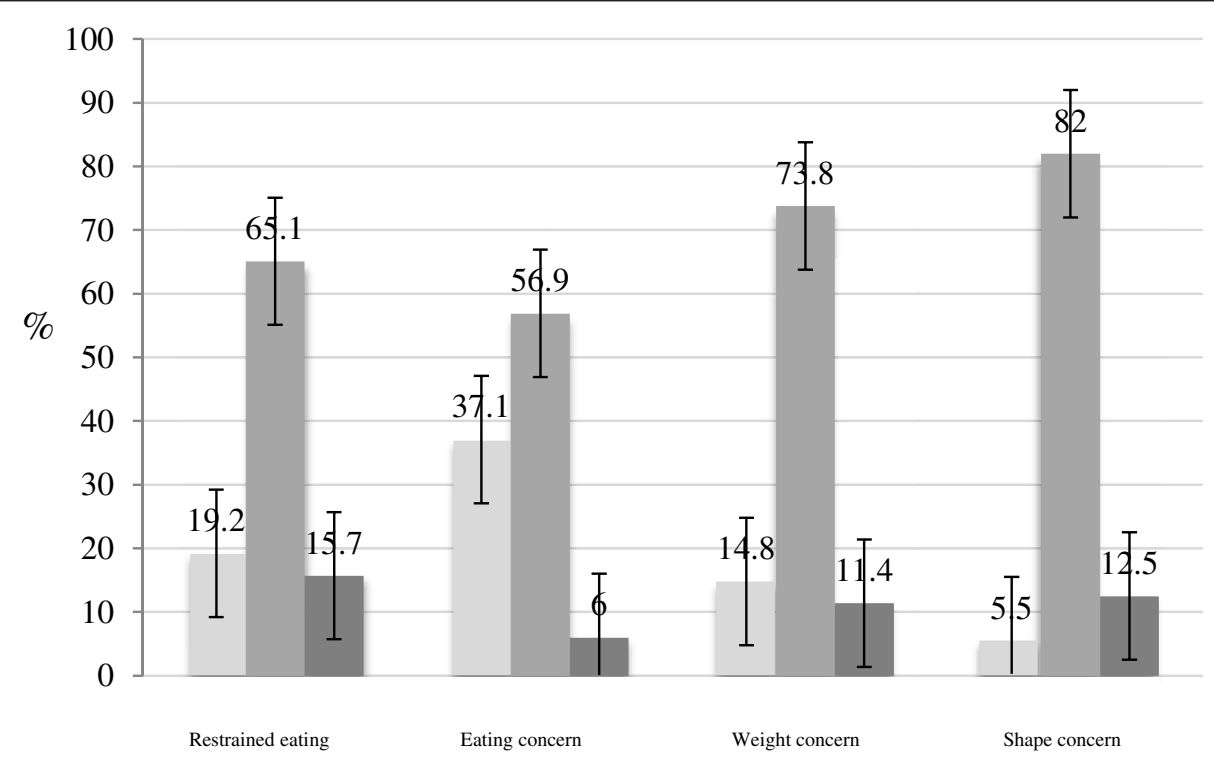

Mean of Restrained eating, Eating concern, Weight concern \& Shape concern $=0$

Mean of Restrained eating $=0.1-2.6$; Mean of Eating concern $=0.1-1.84$; Mean of

Weight concern $=0.1-3.8 \&$ Mean of Shape concern $=0.1-3.69$

Mean of Restrained eating $=2.61 \quad-6.0 ;$ Mean of Eating concern $=1.85 \quad-6.0$; Mean

of Weight concern $=3.09-6.0 \&$ Mean of Shape c oncern $=3.7-6.0$

Figure 2 Manifestations of disordered eating behavior. 
Table 2 Correlations between all variables in the study

\begin{tabular}{|c|c|c|c|c|c|c|c|c|c|c|c|}
\hline & & 1 & 2 & 3 & 4 & 5 & 6 & 7 & $M$ & SD & Range \\
\hline 1 & m.status & - & & & & & & & -.087 & .997 & $-1,+1$ \\
\hline 2 & RSE & $-.096^{\mathrm{a}}$ & - & & & & & & 39.351 & 4.717 & $17-50$ \\
\hline 3 & EDE-Q restraint & $.088^{a}$ & -.213 & & & & & & 1.340 & 1.345 & $0-6$ \\
\hline 4 & EDE-Q eating & $.005^{\mathrm{b}}$ & -.396 & .555 & & & & & .467 & .843 & $0-6$ \\
\hline 5 & EDE-Q weight & $.000^{\mathrm{b}}$ & -.333 & .642 & .716 & -.333 & & & 1.281 & 1.280 & $0-6$ \\
\hline 6 & EDE-Q shape & $.012^{b}$ & -.322 & .638 & .701 & .910 & & & 1.651 & 1.451 & $0-6$ \\
\hline 7 & BMI & $.039^{b}$ & $-.043^{b}$ & .200 & .267 & .456 & .427 & - & 23.495 & 4.144 & $14-46$ \\
\hline 8 & WHR & $.096^{\mathrm{b}}$ & $-.027^{b}$ & $.032^{\mathrm{b}}$ & $.063^{b}$ & $.142^{\mathrm{a}}$ & .186 & .283 & .8182 & 0.081 & $.45-1.27$ \\
\hline
\end{tabular}

Note: Unless otherwise noted, all coefficients were significant at the $\mathrm{p}=.001$ level; ${ }^{\mathrm{a}}$ : significant at $\mathrm{p}<.05$; ${ }^{\mathrm{b}}$ : non-significant; m.status $=$ menopausal status; $\mathrm{RSE}=$ Rosenberg Self-Esteem Scale; $E D E-Q$ restraint = subscale restrained eating of the EDE-Q; EDE-Q eating = subscale eating concern of the EDE-Q; $\mathrm{EDE}-\mathrm{Q}$ weight = subscale weight concern of $\mathrm{EDE}-\mathrm{Q} ; \mathrm{EDE}-\mathrm{Q}$ shape = subscale shape concern of the EDE-Q; $\mathrm{BMI}=$ body mass index; WHR = Waist-to-Hip Ratio.

\section{Group differences}

The overall multivariate analyses (Hoteling-Spur) with menopause status as factor and the subscales of EDE-Q and RSE as dependent variables revealed a main effect of menopause status change $[\mathrm{F}(5,562)=2.584, \mathrm{p}=.025$, partial $\left.\eta^{2}=.022\right]$. Results obtained by multivariate ANOVAs indicate that restrained eating in postmenopausal women is increased compared to premenopausal women $\left(F[1,566]=3.931, p=0.048\right.$, partial $\left.\eta^{2}=.007\right)$, and self-esteem is decreased in postmenopausal women $\left(F[1,566]=5.234, p=0.023\right.$, partial $\left.\eta^{2}=.009\right)$. No significant differences in other eating behavior variables, such as eating concern $(F[1,566]=0.087, p=0.768$, partial $\left.\eta^{2}=.000\right)$, weight concern $(F[1,566]=0.006, p=0.936$, partial $\left.\eta^{2}=.000\right)$, and shape concern $(F[1,566]=0.093$, $p=0.761$, partial $\left.\eta^{2}=.000\right)$, were observed between pre- and postmenopausal women (see Table 1). No covariates were included in this multivariate analysis.

Results obtained by univariate ANOVAs with menopause status as factor and BMI as dependent variable indicate that Body mass index (BMI) did not differ between the groups $(F[1,566]=1.284, p=0.258$, partial $\left.\eta^{2}=.002\right)$. Additionally, WHR did not differ between the groups $\left(F[1,330]=3.091, p=0.080\right.$, partial $\left.\eta^{2}=.009\right)$.

Results obtained by univariate ANOVAs with menopause status as factor and restrained eating as dependent variable show that when controlling for BMI, WHR and age, BMI was a significant covariate $(F[1,327]=18.038$, $p=0.000$, partial $\eta^{2}=.052$ ).

The results with the subgroup of women who reported "Extreme dietary restraint" showed a different pattern of findings: The univariate ANOVAs with menopause status as factor and restrained eating as dependent variable show that when controlling for BMI, WHR and age, menopause status $\left(F[1,24]=4.615, p=0.042\right.$, partial $\left.\eta^{2}=.161\right)$ and WHR $\left(F[1,24]=5.406, p=0.029\right.$, partial $\left.\eta^{2}=.184\right)$ were significant predictors of restrained eating.

Results obtained by univariate ANOVAs with menopause status as factor and self-esteem as dependent variable show that when controlling for BMI, WHR and age, menopause status $(F[1,327]=5.789, p=0.017$, partial $\left.\eta^{2}=.017\right)$ is a significant predictor of self-esteem.

\section{Associations between self-esteem and restrained eating $U$-shaped association between self-esteem and restrained eating}

Results from the multiple regression analysis with selfesteem and self-esteem squared as independent variables and restrained eating as dependent variable are shown in Table 3 and suggest a U-shaped relationship (see Figure 3). Overall, self-esteem explained $6.1 \%$ of the variance in restrained eating.

A mediation analysis with menopause status as an independent, restrained eating as a dependent variable and self-esteem as potential mediator based on the Baron \& Kenny [36] and Sobel method [37] suggested that selfesteem mediated the relationship between menopause status and restrained eating. However, the bootstrapping approach by Preacher and Hayes ([38], and as available as an SPSS-syntax on their homepage, http://www. afhayes.com/spss-sas-and-mplus-macros-and-code.html) did not provide significant results. We, thus, do not further interpret the results from the aforementioned mediation analyses.

\section{Discussion}

This study focused on the role of menopausal status and self-esteem in terms of their relationship with eating behavior in normal-weight middle-aged women. Overall,

Table 3 Multiple regression analysis with restrained eating as dependent variable

\begin{tabular}{lllll}
\hline & $\begin{array}{l}\text { Unstandardized } \\
\text { coefficients, } \boldsymbol{B}\end{array}$ & SE & $\begin{array}{l}\text { Standardized } \\
\text { coefficients, } \boldsymbol{\beta}\end{array}$ & $\begin{array}{l}\text { Level of } \\
\text { significance, } \boldsymbol{p}\end{array}$ \\
\hline Constant & 9.566 & 1.946 & .000 \\
RSE & -.382 & 105 & -1.340 & .000 \\
RSE $^{2}$ & .004 & .001 & 1.134 & .002 \\
\hline
\end{tabular}

Note: RSE $=$ Rosenberg Self-Esteem Scale. 


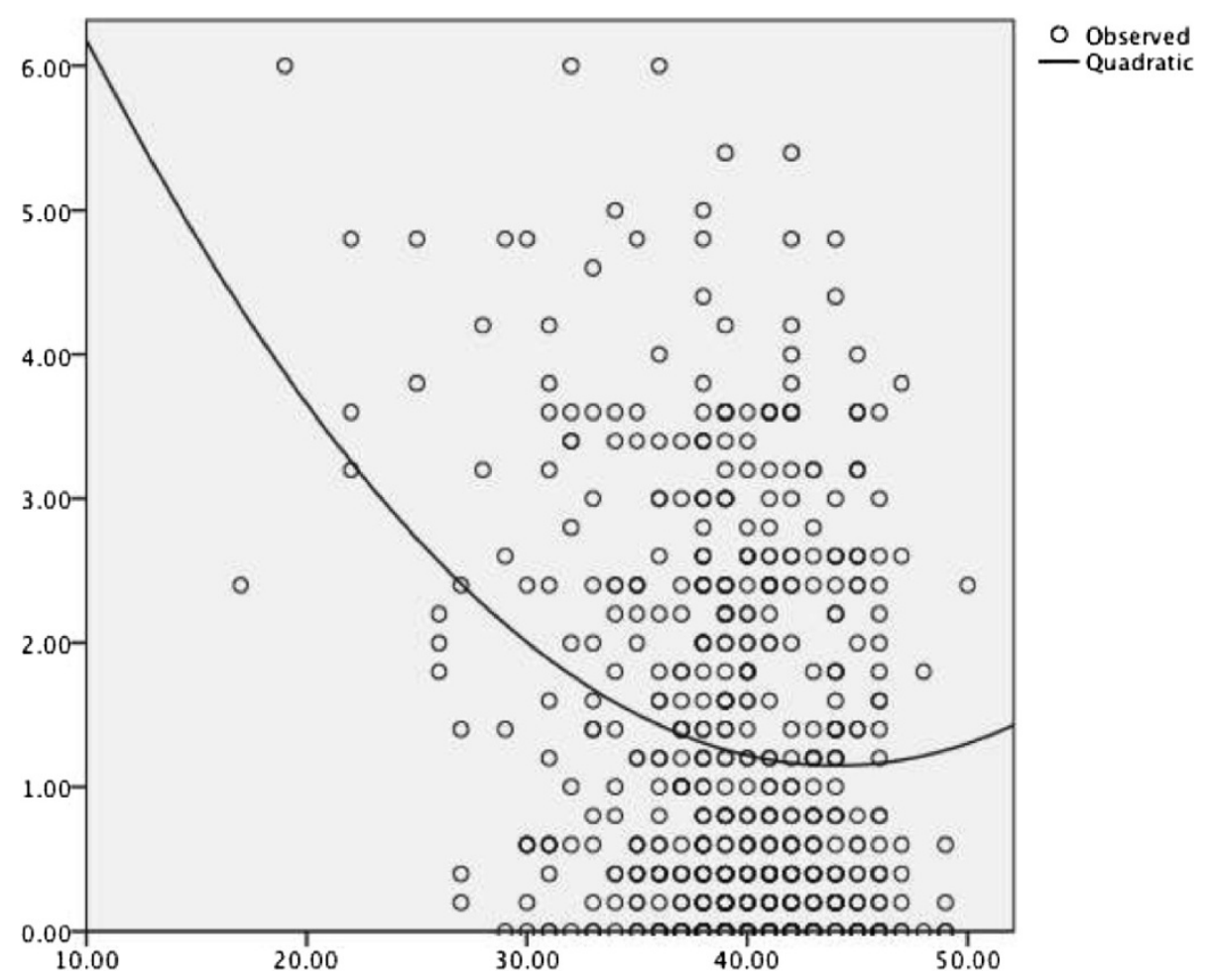

Figure $3 \mathrm{U}$-shaped relationship between self-esteem and restrained eating.

the results suggest that restrained eating is a relavitely frequent behavior among middle-aged women: $15.7 \%$ of all participants report restrained eating scores in a clinically meaningful range. In addition, $10.8 \%-13.3 \%$ of all participants showed a regularly occurrence of binge eating symptoms. Compared to premenopausal women, postmenopausal women report a decreased self-esteem and higher levels of restrained eating, whereas this effect disappears when BMI and age are controlled for. However, even when controlling for BMI, WHR and age, both menopause status and WHR seem to be in a relationship with extreme dietary restraint. Self-esteem was associated with restrained eating, showing a U-shaped curve. Based on these data, it might be followed that self-esteem mediates the relationship between menopausal status and restrained eating, however the results of the additional mediation analyses were inconsistent.

The assessed mean scores of the subscales of the EDE-Q indicate that middle-aged women's eating concerns are comparable with those of young adult women [31]. However, to date, no normative data for this older age group are available. In the present study, a subsample of $6-15.7 \%$ women showed subscale scores in a clinically meaningful range, thus suggesting that negative body image and eating disorders may appear in older women $[39,40]$.
Even tough a recent study examined overweight middleaged participants and showed increased restrained eating in postmenopausal women, our finding that normalweight postmenopausal women show increased restrained eating when not controlling for BMI could be seen in a similar line [41]; we have also found an associtation between menopausal status and restrained eating.

The authors described that postmenopausal women $(\mathrm{M}=51.7$ years) reported higher levels of dietary restraint than premenopausal women $(\mathrm{M}=35.7$ years). However, in that study, postmenopausal women still had a significantly higher BMI than premenopausal women. To the best of our knowledge, this is the first study in this field, examining participants with normal weight. Although restrained eating and BMI are modestly positively correlated, it is highly surprising that restrained eating differs between the average normal-weighted preand postmenopausal women. This finding might have interesting implications for further studies.

Furthermore, menopause-related changes in body fat distribution or increasing BMI in middle-aged women are seen as having a negative impact on appearance $[42-44,25]$. Beyond this, the physiological changes after menopause could be associated with increased feelings of body dissatisfaction and lower psychological wellbeing than in the years before menopause $[45,46]$. When 
internalized ideals of appearance no longer seem achievable [45], this may affect body image and eating behaviors. This effect seems to be even greater the more physical appearance is seen as an integral part of the self-concept [46].

It is difficult to distinguish the association between menopause and restrained eating or BMI from age or age-related factors, such as sedentary lifestyle, slowed metabolism, or less sleep. All of these factors have independently been associated with weight gain [47]. Indeed, our data suggest that postmenopausal women showed higher restrained eating and, when controlling for BMI, WHR and age, only BMI seems to be in a modest positive relationship with restrained eating in middle-aged women. Previous research suggests positive [48], negative [49], or no relationships between BMI and restrained eating. However, in normal-weight groups, restrained eating and BMI seem to be positively associated $[48,50,51]$. It might therefore follow that in normal-weight populations, restrained eating may serve as a marker for the tendency to overeat which could then call for constant counter-regulation.

In younger women, several studies have shown that decreased self-esteem is a risk factor for developing disordered eating behavior [22]. However, results regarding this relationship in middle-aged women have been inconsistent, with some suggesting a positive and some a negative relationship [26,52]. The U-shaped relationship found in the present study now suggests that low as well as high self-esteem might be associated with restrained eating, although the findings are more robust for the former. This finding seems to integrate the previous and seemingly contradictory results. Many women seem to link their self-esteem to their appearance. The realization that one is no longer able to fulfill societal ideals of appearance was found to have a negative impact on selfesteem [46]. Given that restrained eating is intended to maintain or decrease a particular weight [22], and weight loss was found to improve self-esteem [53], increased restrained eating could be regarded as a measure to raise self-esteem [54].

However, the results should also be interpreted in light of the study's strengths and limitations. Online-based data collection allows access to a broad sample of participants as well as the assessment of data in a short period of time [55]. Nevertheless, this is a cross-sectional study and the results should be interpreted with caution because our results show only associations without causal meanings; only longitudinal study might provide more conclusive answers to the question of whether menopausal status and self-esteem might cause disordered eating in middle-aged women. Furthermore, potential problems with online recruitment may occur. Online studies are based on self-reported data, which leads to the inability to verify the inclusion and exclusion criteria.
In addition, individuals with high BMI or circumferences might not want to share this information, even if it is anonymous. For example, even tough we tried to provide a clear definition of the WHR measurement, it might be subjective what the "widest portion of the buttocks" is, and therefore cause biased results. Overall, the recruited participants might be a biased selective population. It could also explain why the BMI is in a normal weight range. In addition, mixing potential perimenopausal and postmenopausal women may have biased the results - a limitation which is due to our online assessment lacking an endocrine validation of menopausal status. We acknowledge that future and methodological more rigorous studies in this field might use endocrine assessments. However, with this initial investigation in this relatively large sample, endocrine analyses would not have been feasible.

Moreover, participants in this online study may have reported specific eating behaviors as a consequence of their educational and professional background.

\section{Conclusions}

In conclusion, this study focused on menopausal status, self-esteem and eating patterns in middle-aged women, and in so doing, might shed light on this relatively understudied topic. It shows that not only women with diagnosed eating disorders may show eating-related changes, but also non-diagnosed, healthy, middle-aged and normal-weighted women may have increased scores, especially in restrained eating. It remains to be analyzed whether it is specifically menopausal status or other agerelated factors, which influence self-esteem in middleaged women. As described in a recent study, it can be hypothesized that menopausal transition could represent a window of vulnerability to eating-related changes [56]. In Western societies, menopausal transition is often perceived as a time of emotional and physical health impairment [43]. Independently, disordered eating is influenced by a multitude of bio-psycho-social factors [24,57]. Thus, while not every woman is necessarily predisposed to developing restrained eating patterns during her menopausal transition, her experienced self-esteem might influence this relationship. According to recent data, over $70 \%$ of women aged over 50 years report dissatisfaction with their current weight and shape, being compared to when they have younger [58], likely, being vulnerable to develop disordered eating. This suggests that women in midlife might be particularly vulnerable to developing disordered eating behavior. Further studies could help identify specific risk groups for disordered eating in this age group, in order to develop prevention and treatment options for the most vulnerable. With increased ageing in our societies and stable youth-related norms of attractiveness, the demand 
for such interventions might well increase over the coming years.

\section{Competing interests}

The authors declare that they have no competing interests.

\section{Authors' contributions}

SD designed the study, recruited the participants, analyzed the data and wrote the manuscirpt. SA helped to recruite the participants and analyze the data. BD supervized the data analysis and edited the manuscript. BTC was involved in the discussion of the data analysis and its implications. UE designed the study with SD, supervised it and edited the manuscript. She was the chief supervisor of the study and manuscript. All authors read and approved the final manuscript.

\section{Acknowledgements}

The authors would like to thank all the women who participated in this study. There were no funding sources for this project.

\section{Author details}

'Department of Psychology, Division of Clinical Psychology \& Psychotherapy, University of Zurich, Binzmuehlestrasse 14/26, Zurich 8050, Switzerland. ${ }^{2}$ Department of Psychology, Division of Clinical Psychology \& Psychotherapy, Albert-Ludwigs University, Engelbergerstrasse 41, Freiburg 79106, Germany. ${ }^{3}$ Institute of Medical Psychology in the Center for Psychosocial Medicine, University Hospital Heidelberg, Bergheimer Str. 20, Heidelberg 69115, Germany.

Received: 28 October 2013 Accepted: 14 August 2014

Published online: 14 October 2014

\section{References}

1. Slevec JH, Tiggemann M: Predictors of body dissatisfaction and disordered eating in middle-aged women. Clin Psychol Rev 2011, 31:515-524. doi: 10.1016/j.cpr.2010.12.002.

2. Wilson GT, Becker CB, Heffernan K. Eating disorders. In Child Psychopathology. 2nd edition. Edited by Mash El, Barkley RA. New York: Guilford Press; 2003:687-715.

3. Association AP: Diagnostic and Statistical Manual of Mental Disorders (4th ed. TR). Washington DC: Author; 2000.

4. Pereira RF, Alvarenga M: Disordered eating: identifying, treating, preventing, and differentiating it from eating disorders. Diabetes Spectrum 2007, 20:141-148.

5. Machado PPP, Machado BC, Gonçales S, Hoek HW: The prevalence of eating disorders not otherwise specified. Int J Eat Disord 2007, 40:212-217.

6. Zerbe K, Domnitei D: Eating disorders at middle age, part 1. Eat Disord Rev 2004, 15:1-3.

7. Procopio CA, Holm-Denoma JM, Gordon KH, Joiner TE: Two-three-year stability and interrelations of bulimotypic indicators and depressive and anxious symptoms in middle-aged women. Int J Eat Disord 2006, 39:312-319.

8. Cumella EJ, Kally Z: Comparison of middle-age and young women inpatients with eating disorders. Eat Weight Disord 2008, 13:183-190

9. Cumella EJ, Kally Z: Profile of 50 women with midlife-onset eating disorders. Eat Disord 2008, 16:193-203. doi: 10.1080/10640260802016670.

10. Stice E, Ng J, Shaw H: Risk factors and prodromal eating pathology. J Child Psychol Psychiatry 2010, 51:518-525. doi: 10.1111/j.1469-7610.2010.02212.x.

11. Burger KS, Stice E: Relation of dietary restraint scores to activation of reward-related brain regions in response to food intake, anticipated intake, and food pictures. Neuroimage 2011, 55:233-239. doi: 10.1016/j. neuroimage.2010.12.009.

12. Field $A E$, Austin $S B$, Taylor $C B$, Malspeis $S$, Rosner B, Rockett HR, Gillman MW: Relation between dieting and weight change among preadolescents and adolescents. Pediatrics 2003, 112:900-906.

13. Stice E, Presnell K, Shaw H, Rohde P: Psychological and behavioral risk factors for onset of obesity in adolescent girls: a prospective study. J Consult Clin Psychol 2005, 73:195-202.

14. Nelson HD: Menopause. Lancet 2010, 371:760-770. doi: 10.1016/S0140-6736 (08)60346-3.

15. Wing RR, Matthews KA, Kuller LH, Meilahn EN, Plantinga PL: Weight gain at the time of menopause. Arch Intern Med 1991, 151:97-102.

16. Polotsky HN, Polotsky AJ: Metabolic implications of menopause. Semin Reprod Med 2010, 5:426-434. doi: 10.1055/s-0030-1262902.
17. Swami V, Frederick DA, Aavik T, Alcalay L, Allik J, Anderson D: The attractive female body weight and female body dissatisfaction in 26 countries across 10 world regions: results of the international body project I. Pers Soc Psychol Bull 2010, 36:309-325. doi: 10.1177/0146167209359702.

18. Tunaley JR, Walsh S, Nicolson P: I' I'm not bad for my age': the meaning of body size and eating in the lives of older women. Ageing Society 1999, 19:741-759

19. Koch PB, Mansfield PK, Thurau D, Carey M: "Feeling Frumpy": the relationship between body image and sexual response changes in midlife women. J Sex Res 2005, 42:215-223.

20. McCabe MP, Ricciardelli LA, James T: A longitudinal study of body change strategies of fitness center attendees. Eat Behav 2007, 8:492-496.

21. Thornton B, Moore S: Physical attractiveness contrast effect: implications for self-esteem and evaluations of the social self. Pers Soc Psychol Bull 1993, 19:474-480.

22. Stice $E$ : Risk and maintenance factors for eating pathology: a meta-analytic review. Psychol Bull 2002, 28:825-848.

23. Leary MR, Baumeister RF: The nature and function of self-esteem: sociometer theory. Soc Psychol 2000, 32:1-62.

24. LePage ML, Crowther JH, Harrington EF, Engler P: Psychological correlates of fasting and vigorous exercise as compensatory strategies in undergraduate women. Eat Behav 2008, 9:423-429. doi: 10.1016/j.eatbeh.2008.06.002.

25. Tylka TL, Sabik NJ: Integrating social comparison theory and self-esteem within objectification theory to predict women's disordered eating. Sex Roles 2010, 63:18-31.

26. Green SP, Pitchard ME: Predictors of body image dissatisfaction in adult men and women. Soc Behav Pers 2003, 31:215-222.

27. Webster J, Tiggemann M: The relationship between women's body satisfaction and self-image across the life span: The role of cognitive control. J Genet Psychol 2003, 162:241-252.

28. WHO: Waist Circumference and Waist-Hip Ratio, Report of a WHO Expert Consultation. Geneva: World Health Organization (WHO); 2012.

29. Fairburn CG, Beglin SJ: Assessment of eating disorders: interview or self-report questionnaire? Int J Eat Disord 1994, 16:363-370.

30. Hilbert A, Tuschen-Caffier B, Karwautz A, Niederhofer H, Munsch S: Eating disorder examination-questionnaire. Evaluation der deutschsprachigen Übersetzung Diagnostica 2007, 53:144-154.

31. Mond JM, Hay PJ, Rodgers B, Owen C: Eating Disorder Examination Questionnaire (EDE-Q): norms for young adult women. Behav Res Ther 2006, 44:53-62.

32. Cooper Z, Fairburn CG: Refining the definition of binge eating disorder and nonpurging bulimia nervosa. Int J Eat Disord 2003, 34:S89-S95.

33. Carter JC, Stewart DA, Fairburn CG: Eating disorder examination questionnaire: norms for young adolescent girls. Behav Res Ther 2001, 39:625-632.

34. Janich H, Boll T: Übersetzung des Self-Esteem Fragebogens von Rosenberg (1965). Trier: Universität Trier, Fachbereich I - Psychologie; 1982. unpublished manuscript.

35. Rosenberg M: Society and the Adolescent Self-Image. Princeton, N.J.: Princeton University Press; 1965

36. Baron RM, Kenny DA: The moderator-mediator variable distinction in social psychological research: conceptual, strategic, and statistical considerations. J Pers Soc Psychol 1986, 51:1173-1182.

37. Sobel ME: Asymptotic confidence intervals for indirect effects in structural equation models. In Sociological Methodology. Edited by Leinhardt S. Washington, DC: American Sociological Association; 1982:290-312.

38. Preacher K, Hayes AF: SPSS and SAS procedures for estimating indirect effects in simple mediation models. Behav Res Method Ins Comp 2004, 36:727-731.

39. Gadalla TM: Eating disorders and associated psychiatric comorbidity in elderly Canadian women. Arch Womens Ment Health 2008, 11:357-362. doi: 10.1007/s00737-008-0031-8.

40. Mangweth-Matzek B, Rupp Cl, Hausmann A, Assmayr K, Mariacher E, Kemmler G, Whitworth AB, Biebl W: Never too old for eating disorders or body dissatisfaction: A community study of elderly women. Int J Eat Disord 2006, 39:583-586.

41. Copeland AL, Martin PD, Geiselman PJ, Rash CJ, Kendzor DE: Predictors of pretreatment attrition from smoking cessation among pre- and postmenopausal, weight-concerned women. Eat Behav 2006, 7:243-251.

42. McKinley NM: The developmental and cultural contexts of objectified body consciousness: a longitudinal analysis of two cohorts of women. Dev Psychol 2006, 42:679-687. 
43. Mcquaide S: Women at midlife. Soc Work 1998, 43:21-31.

44. McLean SA, Paxton SJ, Wertheim EH: Factors associated with body dissatisfaction and disordered eating in women in midlife. Int J Eat Disord 2010, 43:527-536. doi: 10.1002/eat.20737.

45. Cash TF, Melnyk SE, Hrabosky Jl: The assessment of body image investment: an extensive revision of the appearance schemas inventory. Int J Eat Disord 2004, 35:305-316.

46. McKinley NM, Lyon LA: Menopausal attitudes, objectified body consciousness, aging anxiety, and body esteem: European American women's body experiences in midlife. Body Image 2008, 5:375-380. doi: 10.1016/j.bodyim.2008.07.001.

47. Filozof $C$, Gonzalez C: Predictors of weight gain: the biological Behavioral debate. Obes Rev 2000, 1:21-26.

48. de Lauzon-Guillain B, Basdevant A, Romon M, Karlsson J, Borys JM, Charles MA: Is restrained eating a risk factor for weight gain in a general population? Am J Clin Nutr 2006, 83:132-138.

49. Boschi V, lorio D, Margiotta N, D'Orsi P, Falconi C: The three- factor eating questionnaire in the evaluation of eating behaviour in subjects seeking participation in a dietotherapy programme. Ann Nutr Metab 2001, 45:72-77.

50. Williamson DA, Lawson OJ, Brooks ER, Wozniak PJ, Ryan DH, Bray GA, Duchmann EG: Association of body mass with dietary restraint and disinhibition. Appetite 1995, 25:31-41.

51. Bellisle F, Clement K, Le Barzic M, Le Gall A, Guy-Grand B, Basdevant A: The eating inventory and body adiposity from leanness to massive obesity: a study of 2509 adults. Obes Res 2004, 12:2023-2030.

52. Johnson F, Pratt M, Wardle J: Dietary restraint and self-regulation in eating behavior. Int J Obes 2012, 36:665-674. doi: 10.1038/ijo.2011.156.

53. Vasiljevic N, Ralevic S, Kolotkin RL, Marinkovic J, Jorga J: The relationship between weight loss and health-related quality of life in a Serbian population. Eur Eat Disord Rev 2012, 20:162-168. doi: 10.1002/erv.1114.

54. Crocker J, Park LE: Seeking self esteem: Construction, maintenance and protection of self-worth. In Handbook of Self and Identity. Edited by Leary MR, Tangney JP. New York: The Guilford Press; 2003:291-313.

55. Reips UD: Standards for Internet-based experimenting. Exp Psychol 2002, 49:243-256.

56. Mangweth-Matzek B, Hoek HW, Rupp Cl, Kemmler G, Pope HG Jr, Kinzl J: The menopausal transition-a possible window of vulnerability for eating pathology. Int J Eat Disord 2013, 46:609-616. doi: 10.1002/eat.22157.

57. Hunter M, Rendall M: Bio-psycho-socio-cultural perspectives on menopause. Best Pract Res Clin Obstet Gynaecol 2007, 21:261-274.

58. Gagne DA, Von Holle A, Brownley KA, Runfola CD, Hofmeier S, Branch KE, Bulik CM: Eating disorder symptoms and weight and shape concerns in a large web-based convenience sample of women ages 50 and above: results of the gender and body image (GABI) study. Int J Eat Disord 2012, 45:832-844. doi: 10.1002/eat.22030. Unipark [http://www.unipark.info/1-0online-befragungssoftware-fuer-studenten-und-universitaeten-unipark-home $\mathrm{htm}$ ] SPSS Syntax [http://www.afhayes.com/spss-sas-and-mplus-macros-andcode.html]

doi:10.1186/s40337-014-0023-

Cite this article as: Drobnjak et al:: Restrained eating and self-esteem in premenopausal and postmenopausal women. Journal of Eating Disorders 2014 2:23.

\section{Submit your next manuscript to BioMed Central and take full advantage of:}

- Convenient online submission

- Thorough peer review

- No space constraints or color figure charges

- Immediate publication on acceptance

- Inclusion in PubMed, CAS, Scopus and Google Scholar

- Research which is freely available for redistribution 